\title{
The Construction of Professional Identity of Beginning University Teachers - Two Cases Studies from Tunisia
}

\author{
Hejer Ben Jomâa
}

Higher Institute of Sport and Physical Education of Tunis, Manouba University.

UMR EFTS, Jean-Jaures Toulouse University, UR ECOTIDI (UR16ES10). Virtual University, Tunisia.

Salma Majdoub

UR ECOTIDI (UR16ES10). Virtual University, Tunisia.

Hiba Abdelkafi Karoui

Higher Institute of Sport and Physical Education of Sfax, Sfax University. UR ECOTIDI (UR16ES10). Virtual University, Tunisia.

Georges KPAZAÏ

School of Human kinetics, Laurentian University, Sudbury (ON), Canada.

\begin{abstract}
This article examines the relationship that may exist between the "link to knowledge" and "professional identity" which refers to the process through which the beginning university teacher can or cannot identify himself professionally. These different relationships determine the identity construction process of beginning university teachers, which is constructed in and through his experience. We used the study of "case by case" and "one by one" (Terrisse, 2009) within a clinical didactic methodology. It is about an in depth study of a "singular, divided and subjected" subject which relies on qualitative study method". The data analysis is organised through three important tenses: the already-there, the test and the post-stroke". The originality of our study is to analyse the identity construction process of two beginning university teachers in the region of Tunis, through a crossed case study. The in situ observation of four theoretical, the semi-structured interviews (a priori, ante and post session and post-stroke) and the continent analysis, allow us to unveil the mechanism (conscious and unconscious) of the identity construction of these beginning university teachers as well as its evolutionary and moving dynamics especially at the first years in teaching job.
\end{abstract}

Keywords: Clinical didactics; university pedagogy; professional identity; beginning university teacher. 


\section{Introduction}

Over the last few years, the aim of many researchers to enhance the professionalization of university teachers in teaching jobs has increased. In fact, the notion of professionalization englobes three different fields: social, training and job (Wittorski, 2008). Initial training in universities is a major determinant in having future professional workers and teachers. The university pedagogy has newly emerged to seize the problematic of training activities (Frenay \& Paquay, 2011) in general and its role in the professionalization of future workers in particular. Indeed, the main focus of the university pedagogy is based on one hand on the university teacher and on the other hand on the different elements that structure the educational development. According to Frenay and Wouters (2014, p. 201):

"The field of university pedagogy looks at the questions connected to the activities of training, to the results of these activities (success-failure, learning, development of skills etc.), to the curricula and to the contextual and institutional variables (context of the student, the teacher, political, social, cultural factors etc."

In order to encompass the context of the university teacher, it is necessary to understand the different elements related to his teaching conceptions, his personal engagement and motivation, his expertise, and his teaching experiences and paths. These elements shape in one way or another his professional identity in the teaching job domain.

According to Dubar (1991), "the identity is never given, it is always constructed and reconstructed within an uncertainty which is more or less big, and more or less stable". Each individual is defined and recognised through his way to think and to act. He is constructed through different rhythm according to his own personality and the events that he experienced in his life. The identity is being a central concept that defines the person as well as his internal sense "of a unit of coherence, belonging, value, autonomy and confidence organised around a will of existence" (Mucchielli, 1986). The individual perceive himself as "a singular one, which is necessary to suppose his historical identity" (Labarrière, 1990). This current paper seeks to consider those complex situations throughout teaching practice under a double epistemological affiliation: the didactic and the clinic from a psychanalytic inspiration (Terrisse \& Carnus, 2009). Our main preoccupation is to encompass the singularity of the teachers as well as the being taught (in our case university students) taken by the didactic. This scientific orientation offers some heuristic analysis tools such as "the link to knowledge", "the subject supposed to know" and 'the decisional already-there".

The clinical anchoring of our case study is justified through an in-depth analysis of some didactical, pedagogical, epistemological and singular dimensions of teaching action in higher education. In this respect, we emphasise that beginning university teacher's professional identity study draws from the professional development process of these teachers. Thus, this study targets teaching training domain. In fact, knowing others has an important role in building the 
"professional self" which allows the beginning university teacher to be progressively affiliated in his job. It allows him also to develop new didactical, pedagogical and professional competences which will help him to "be capable" and to "be recognized" (Ricoeur, 2005).

Taking into account external and internal determinants of the beginning university teacher's identity construction process allows to get intelligible and operational indicators in order to enhance the continuing education of university teachers and their professional development.

\section{Problem and research questions}

To fulfil the quest of ensuring and affirming his position as a professional teacher, the beginning university teacher feels a sort of "isolation" (Martuccelli, 1995) and a "professional identity crises" (Blanchard-Laville, 2002) when he is faced to this complex situation. As for him, professorial and teaching practice presents a critical moment to discover and to learn new things about this job (Durand, 1996). These quandaries are so subjective for these teachers, as they look for over compensating temporary difficulties (Vygostski, 1994). Indeed, the beginning teacher looks for benchmarks in over and for the action, in order to develop the expected competences of a professional teacher and to draw his own personal path.

From this problematic, we can formulate our research questions as follows:

1) How does the beginning university teacher learn to teach, construct and professionally identify himself?

2) How can his link to knowledge (teaching conceptions) influence his way to teach as well as his didactic-pedagogical action?

\section{Conceptual framework}

This study questions "in situ" teaching practice while taking into account the subjectivity of the teacher subject taken into the didactical system (Terrisse \& Carnus, 2009). We focus on newly appointed teachers in universities. These teachers are asked to update and to complete their knowledge in order to succeed in their professional carrier and to progress in teaching practice as

"... the new teacher tries to incorporate what he has observed into his own classroom, but the lesson does not flow smoothly and challenging discipline problems crop up at prime learning moments, diverting his attention and disrupting the environment he had worked so hard to achieve "(Abha, \& Megan, 2015).

Similarly, he begins to follow the norms, values and difficulties that he faces throughout his early carrier. He can also be faced with a loss of markers which shows that the identity is considered as an uncompleted part of the individual. This part is mostly threatened and always reconstructed. 


\section{-The professional identity:}

Historically, the notion of professional identity has first emerged in Sainsaulieu's (1977) publishing which treats the issue of the difference of power relationship experiences in both public and private working environments and its role in the construction of the professional identity. As for Dubar (1991), the professional identity is about the fusion between the "virtual identity" and the "real identity" which are constructed through a previous professional path. To seize this professional identity, it is necessary to take into account all the knowledge, competence and the self-image as its principle and inescapable components. In this context, two principle types of identities can be distinguished: the identity of other and the biographical and relational identity for oneself.

The professional identity leads to the identification of the generic lines of individuals belonging to the same job, as well as the social representations that others have about them. Indeed, "that what makes members of the same profession recognize themselves and their specifications outside. It supposes, on one hand a double intern unification work, on the other hand an extern recognition" (Ion, 1990, p 91). The construction of the professional identity of the teachers as well as other professions, is related to the social representation that the teacher has regarding his job. In other words, it is the construction of his image in regards to himself and what he thinks that others think of him (Mead, 1934 ; Dubar, 1991 ; Tickle, 2000). It can be developed all along his career with all different events and incidents that he experiences.

In order to encompass the concept of teacher's professional identity, we refer to both didactical and clinical analysers:

\section{-The link to knowledge:}

Is the way by which the teacher conceives his teaching act or his teaching conception (Beaucher, 2010; Rochex, 2004). It is also an "amount of images, expectations and judgments about the sense and social function of knowledge and school, about the taught discipline, about learning situation and oneself" (Charlot, 1982). According to De Léonardis, Laterrasse and Hermet (2002), the link to knowledge "is the way by which the teacher conceives and deals with the activity that he teaches at the time of knowledge transmission". It is a progressively enhancing process all along the professional life through several personal experiences that can influence the way the individual conceives the knowledge. These personal experiences make of the teacher as a singular and unique individual depending on his personal history. As it presents "a particular moment of individual's history in a particular place and time, his link to others, to the world and to himself" (Charlot, 1997). According to Chevallard (2002), the concept of the "link to knowledge" has three different registers: the official link to knowledge, the personal link to knowledge and the institutional link to knowledge. In our study, we choose to keep only two registers for the analysis which are the personal link to knowledge and the official link to knowledge. 


\section{-The "supposed to know subject" (Sujet supposé savoir):}

Originally, it is a psychanalytic analyser created by Lacan (1968) and then redesigned by Chevallad (2002) as part of his anthropological theory of the didactic. It was also used by the members of EDIC (clinical didactic team) especially in the studies of Terrisse and Carnus (2009) and Carnus and Terrisse (2013). This concept considers that he teacher subject is judged as a "supposed to know subject". This contingency is an integral part of the didactical situation. It corresponds to the gap between what the teacher expects to transmit and what he really transmits while class time. As he keeps a symbolic position in regards to his students because he cannot master all the knowledge in a didactical way. Thus, we refer to this clinical analyzer in order to see what is the position that the teacher assumes in regards to knowledge ones he is faced to the time of knowledge transmission in class.

\section{Method}

In this paper, we are going to focus on the professional identity construction process Known as "a continuous and mutuel interaction system ". In order to encompass this evolutionary system, we observed in situ the studied object and noticed all its modifications and evolution throw a clinical didactic methodology. In the following paragraphs we will present the particularity and the rigor of our method choice trying to answer our research questions.

\section{Research participant}

Two beginning university teachers participated in our study based on their availability and cooperation: Sarra and Sabri. They both teach in the high institute of sports and physical education of Tunis and have the same university degree (University Assistant). The following table explains the profile of these two beginning teachers (see table. 1)

\begin{tabular}{lll}
\hline Teachers & Teacher 1: Sarra & Teacher 2: Sabri \\
\hline University degree & Assistant & Assistant \\
Gender & Female & Male \\
Seniority & $1^{\text {st }}$ year & $1^{\text {st }}$ year \\
Speciality & Cognitive Psychology & $\begin{array}{l}\text { Didactic and Pedagogy of Physical } \\
\text { Education }\end{array}$
\end{tabular}

\section{Data collection}

For our data collection, we filmed in situ two regular lecture courses for each teacher which took place in Tunis between the 20th of January and the 16th of Mai 2016. Each course lasts one hour and a half. We also register all the verbatim said while all sessions using a lavalier microphone in order to capture all the instructions and verbal exchanges with their students. 
The collected verbatim were completely transcribed and coded in order to enhance the post-stroke and to be able to cross the results arising from the a priori analysis to interpret them (Touboul, 2011). We proceeded above all with a pre-observation (or pre-experimentation) of one lesson for each teacher taking into account the research ethical considerations. This procedure allows the teachers as well as the students to get used to the presence of the camera in order to minimize the "camera effect" and for us to test the methodological device. We also used several investigation technics such us: in situ observation, interviews and the content analysis (Van Der Maren, 1996; Bardin, 1998).

The data collection is set up over three different tenses according to the clinical didactic methodology: The already-there (before), the test (during) and the poststroke (after). At the first tense (the already-there) we used semi-structured interviews which were totally recorded. At the second tense (the test), we filmed four entire theoretical lessons for each teacher with two interviews before and after each lesson. Finally, for the third tense (the post-stoke) we used a semistructured interview in order to remote the time of meaning shuffling. The analysis of these three different tenses allows the construction of the case. In our research, the case study is a "detailed" and an "in-depth" analysis (Van Der Maren, 1996) which aims to explore the intelligibility of the observed teaching practices. In fact, Passeron and Revel (2005), who looked for the "rehabilitation" of the case study, considers that "sciences of the case have ensured the convergence between descriptive value of clinical method and the methodological value of contextualized observation for the production of evidence". This research temporality allows us to access the psychic and the unconscious part of teacher's singular behavior and to identify the remarkable and significant events and facts which are in a direct relation with our research problematic. Finally, we used the data triangulation method (Wanlin, 2007) in order to confirm our results and to ensure more intern scientific validity.

\section{Data analysis}

This particular step of the research requires the connection between the collected data and the studied problematic as well as the assumptions that were formulated at the beginning of the study. As a matter of fact, "to analyse the research's results, consists to make the collected data to speak out in order to confirm or to infirm the research assumption. That's why, it is quiet necessary that the researcher carefully examines his data" (Raymond, Tremblay \& Pierrier, 2006). The content analysis is the most known method which allows the study of interviews and qualitative observation (Krippendorff, 2003). It is the "most objective and trustworthy" (Berelson, 1952) qualitative study method.

Before we begin the analysis process, we have transcribed all the verbatim said by each participating teacher. As "it is preferable to put them on a thorough review by writing them in order to make reading easier and to have a credible track" (Auerbach \& Silverstein, 2003). According to Freud (1985), teacher's verbs and acts that we have extracted, have become essentially the base of "a case construction" in the analysis process. The case study is a methodological tool that enables the dissemination of new or revisited knowledge and the encompassing of the complexity and the singularity of human beings. Indeed, 
this tool enables to make "in-depth" and "detailed" case analysis (Van Der Maren, 1996) and has to be used in a methodical and objective way to get more credible results (Collerette, 1997).

In our context, we do not pretend to generalise our result out coming from these two case studies. But we attempt to bring new and significant results which will contribute to produce new methodological tool as well as more rigorous analysers through what we call it in the clinical didactic setting: the "cumulativeness of results". This procedure will enable researchers in didactics to understand and to know more about teaching practice in all scientific disciplines.

\section{Results:}

In this study, we aim to examine how each beginning university teacher attempts to build his own professional identity through the study of their in situ behavior mostly unconscious, their personal teaching conceptions and the meaning that they give to each act during class. In order to encompass all these analysis elements in a clear way, we are going to present the results of each case separately. This will enable us also to reveal the singular determinants that are characterising each case and finally to make comparative analysis between them.

\section{The case of Sarra}

Sarra is a beginning university assistant trying to adjust and to adapt with her new statue as a university teacher. In the following paragraphs we are going to show the particularity of the case Sarra through the study of her singular link to knowledge and her statue of a "supposed to know subject".

\section{The link to knowledge}

The choice of teaching goals as well as the type and the source of transmitted knowledge made by Sarra shows clearly her official link to knowledge. As a matter of fact, the transmitted knowledge during all sessions originates mostly from her initial training curriculum in university. He explains that "the programs always serve as a guide for him, especially at the beginning of teaching career". Hence, she uses her knowledge of a researcher to update her knowledge to be taught. She also admits that "research has helped her so much, as it provides bases, tools, justifications and results to be capable of teaching in university and to enhance her way to teach".

Although, her personal link to knowledge is progressively developing. Indeed, she estimates her way to recognise her object of knowledge: "I make my own researches in the internet to enrich my courses, I also attend congresses and seminars in order to renew my knowledge". This teacher is constantly looking for creating an interactive conception in regards to her students and for explicitly inviting them to interact and to discuss with each other. As she says to her students during a session: "who can give us a practical example from the field? Come on I am waiting for your answers". This shows clearly that she oscillates between the interactive mode of teaching and the transitive one. 
However, Sarra finds herself obliged to use the transitive mode of teaching when she does not receive any response to her questions. She explains: "I am alone in most situations, talking to myself, the students are not motivated" also when she discovers that her students are not interested in the course that she is giving to them and they do not want to learn. She also insists on knowledge referential when she says: "at the ISSEP, we can teach all the disciplines, we can teach both theoretical and practical element, the knowledge and the know-how". Sarra, attempts to "reach all knowledge domains to be able to answer all student's questions". She wishes to be a "polyvalent" teacher and to interfere in all psychology domains such as: social psychology and cognitive psychology.

\section{The "supposed to know subject"}

Sarra assumes a symbolic position in regards to knowledge and her students as a supposed to know subject. This position is so hard to establish and to maintain. Above all, she is aware that she does not know everything because she is still a beginning teacher and she cannot also teach everything as well. She has got a clear problem while transmitting knowledge to her students especially when they are not interested in learning.

While teaching in class, she looks for creating a sort of dynamic interaction in teaching-learning process, as she says: "these practical examples will contribute to the success of your future professional carrier". She also insists that "it must be a motivating atmosphere in class in order to capture student's attention". At the same time, she tries to adapt her resources with the diversity of students that she has. But, she appears divided between the classroom managing and engaging her student in learning process, as she looks for "positioning" herself in the didactical space of the class.

During teaching, Sarra shows an authority and a rigor in teaching act, but also improved flexibility even she is a new teacher in the domain. She admits: "I always try to find the right solutions to capture the attention of my student, I teach simple things (...) because I want them to understand what I am teaching, I sometimes translate what I am saying to Arabic to ensure a better comprehension. I also give them practical and realistic examples which are related directly to their future professional carrier".

\section{The case of Sabri}

After presenting all the singular elements of case Sarra, we will focus know on the case Sabri in order to seize his own singular factors that may affect his professional identity construction process using the same analysers and then make a comparative analysis.

\section{The link to knowledge}

To access to the link to knowledge of Sabri, we have to examine how he creates links with what he knows and how he extracts the meaning from it. Indeed, we can say that he is infused in his familial experience. He admits: "I was born in a family which its members are all teachers and I fallowed that tradition". His experience 
as a student seems to affect his way to think and to teach, as he explains: "I think well since my first year as a student". As a matter of fact, this teacher devotes a quiet importance to the discipline that he teaches. He describes it like "the spine of the training".

Sabri looks to diversify the personal knowledge that he transmits. He explains:" I am handling my knowledge very well; I try to know what are the new things that must be taught based on scientific research from all over the world". Furthermore, he elaborates his curricula based on official texts and programs as well as the institutional project. This strategy has emerged through the knowledge that he has chosen to teach which originates from official curricula of physical education didactic domain. He implements an official and transitive teaching conception. Then he decides to link the theory with practice in a useful way. Sabri skips from a transitive mode of teaching to an interactive one in order to ensure the dialogue with his students. He clarifies that he "always tries to avoid the permissive mode of teaching". This strategy emerges through his choices of knowledge to teach. We also notice that the goals stem from the filmed sessions figure clearly in the official programs of physical education didactic. As a matter of fact, Sabri combines "scheduling" with "pedagogical action" and teaches what he has really expected as the content that he desires to teach but still remaining his schedule. He claimed: "I have no modification to do in regards to my first schedule that I expected". Then he managed to mix two concepts and/or themes with a third one at the same session in order to implement the idea that everything (themes, concepts, etc.) is connected in his student's minds. He explains: "I have condensed them in a very interesting way to enable the students to see that the courses which they are taking are totally related to each other's". His teaching intention establishes within this fallowing idea: "the reality of things shows that we are turning around one single axis, which is the future of teaching domain", which finally means an institutional, global and formal teaching conception.

\section{The "supposed to know subject"}

The observation and the analysis of the time of test (teaching time) of Sabri, enable us to notice that he tries to assume his didactical responsibility in doing his functions as a teacher. As he says: "I prepare my courses, I try to ensure the right content transmission to my students properly". He tries also to empower and to encourage them by showing them a rewarding image of their learning process. He explains:" I valorise their performances to give them a new sense of things, to capture their attention and to orient them to where I want them to be at the end". Hence he sees his students as "future field teachers". Sabri is quiet conscious about his symbolic position as a "supposed to know subject" and tries to transmit theoretical and practical knowledge to students who are not in class for the same purpose that he has as he admits that: "students nowadays have a very poor performance. They focus only on what we provide them, they do not want to invest, to apply and to look for other types of knowledge. What really matters for them is to get good mark and that is all". 


\section{Comparative analysis}

This qualitative research is interested in the study of two different and singular cases. Despite their differences, these two cases may also have some similarities. In that respect, we used a crossed case study to highlight the singularities and the regularities characterising our cases.

\section{Differences}

Firstly, we focus on the comparative analysis of teaching conceptions of both of the beginning university: Sarra and Sabri, which means their link to knowledge and their teaching mode that they use to "transmit" the knowledge in class. Regarding to Sarra, teaching in university is "an absolute scientific research world which encourages discovery, new strategies and new learning conceptions". This declaration insists her to construct new competences in order to be used in solving problems and difficulties that she faces while doing her daily job. She believes that it is crucial for teachers to become reflexive because their job is considered as a cognitive process and not as daily repletion routine.

The fact of being affected in a university institution pushes her to invest in a significant way in her job as a researcher-teacher.

However, Sabri admits that teaching in university is "a personal vocation" which represents all his life. As a matter of fact, being a university teacher was his dream since his childhood. It is about an identity "choice" which is influenced particularly by his family environment and history. This family "institution" seems to form his professional representations and to determine his way to teach. His teaching conceptions have progressed to be focused on pedagogical and didactical innovation which affects his teaching act.

This fine analysis shows also some differences regarding to their personal opinion about the initial training. Sarra thinks that it is an "ideal" and a "rich" training. As for her, it is an important component and a principal source of knowledge transmission. This theoretical and practical contribution helps her to identify and to construct herself professionally.

Although, Sabri believes that initial training is not completely "trustworthy" and not "enough". As for him, it is not enough because the initial acquired knowledge serves only to the qualification to the professional life. It is only a step that must be completed and readjusted using other sources of information because it is more useful in the continuing training context. Which matters the most for Sabri is his practical personal experience as well as his social affiliation inside his family.

Through these two compared cases studies, we can highlight the significance and the weight of teaching personal conceptions over the professional identity construction process as well as the professional development of the beginning university teachers. 


\section{$\underline{\text { Similarities }}$}

From this comparative analysis, we can also extract some similar features between the practice teaching of these two university beginning teachers. They both have a clear desire of knowledge (Beillerot, 1996) which enhances their link to knowledge and their teaching conceptions. Also, they both look for situating themselves in the space of the classroom and guaranteeing their pedagogical task especially when it comes to class managing. We can also notice that they attribute a remarkable importance to the self-training, the continuing training and the professional development which allow to facing the increasing complexity of teaching act and its moving challenges.

Both teachers claim the lack of student's learning desire and their decreasing investment degree in learning process. This does not match their own teaching desire. In despite of this complex reality and its professional dilemma, they still need to identify themselves professionally and to construct their professional "me" which determines their professorial action. Finally, Sarra and Sabri want to ensure a more significant and motivating learning to their students.

\section{Discussion}

This present study aims to highlight the differences and the similarities of two beginning university teacher's teaching acts in terms of their link to knowledge and their way to teach and to construct themselves professionally. We have chosen some significant extracts from their verbatim to organise them and to construct the "didactical vignette". We use personal/official knowledge dichotomy from the moment when they are faced to the "impossible" test of teaching (Freud, 1925). They cannot pass by their personal and practical lived experiences and their own link to knowledge as well as the transmitted knowledge outcome from their "official" and "institutional" link to knowledge. These experiences are far from the professional environment context since they both are in their first year as university assistants, but more as the personal lived experiences and social contexts related mostly to their student lives during initial training (Beckers, 2007). Beginning university teachers in particular derive their link to knowledge not only from initial training, but also from their experience as researchers and expert in their scientific domain.

These beginning teachers seem to be divided between confirming their statue of a "supposed to know subject" and accepting the reality of "not knowing" (Buznic, 2016, p 409; Ben Jomaa \& Terrisse, 2014). Indeed, the lack of knowledge in some doubting facing situations can generate a sort of instability and uncertainty in the representational relationship with himself. These doubting feelings create an identity crisis that questions and re-questions his symbolic position. They try to establish a new framework which makes possible teaching their students and themselves how to do the job (Saujat, 2004) by negotiating their teaching approaches and to clarifying their knowledge transmission strategies (Trigwell, Prosser \& Waterhouse, 1999).

Professional identity is finally a process which is constructed, forged and modified continuously as long as the teacher is faced to different experiences in 
different times and social context (Barbier, 1996). Then, new social representations will be established, new pedagogical attitudes, teaching conceptions, teaching dynamics and strategies will be created of modified.

\section{Conclusion}

This comparative analysis allowed us to know that the outcome of the singular functioning of the identity process (in our case professional identity) of each teacher makes more sense when we take into account their "already-there" (Carnus, 2001). This personal determinant gathers their personal filters (Loizon, 2009), their singular history, their intern and implicit theory, their link to the taught discipline, their "experiential knowledge" (Buznic, 2009), "experiential transposition" of knowledge (Jourdan, 2005), as well as all the subjective elements of lived experience.

We have highlighted the different links to knowledge (personal and official) which originate mostly from all lived experiences of the teacher especially when we dig deeper in his personal and singular part of, those of didactic subject (Ben Jomaa, Sghaier \& Mami, 2016; Abdelkafi, Ben Jomâa \& Kpazai, 2018) taken in knowledge transmission test.

The subjectivity of both teachers, allowed us to identify the meaning which they attribute to their acts during teaching test time and while they are faced to their own didactical works. We also looked to discover their teaching desire through their link to the discipline, to the student and to the teaching job. These different links determine mostly the professional identity construction process of the beginning university teachers, which is the main purpose of this study.

Through this clinical point of view, we managed to make deeper and finer analysis of the singular and unique functioning of the teaching practice in university settings. This empirical research method allows us to collect different rigorous data away from our emotions and our subjectivity as a researcher. As the data triangulation method contributes to the neutralization of the researcher's subjectivity and offers more credibility and fidelity to our results. Finally, we emphasise that we do not have the intention to generalise these qualitative results. Although, through the cumulativeness of several results, we can produce some theoretical elements based on the scientific validity of the "case" and the methodology rigor which can be transferable and applicable in other disciplinary fields.

\section{References}

Abdelkefi, H., Ben Jomâa, H. \& Kpazai, G. (2018). Teaching Practice between Ostension and Proximity: The Case of a Seasoned Physical Education Teacher in Clinical Didactics. International Journal of Learning, Teaching and Educational Research. 17, 2, pp. 87-98. https://doi.org/10.26803/ijlter.17.2.6

Abha, S \& r Megan, L (2015). Learning as you Teach. International Journal of Learning, Teaching and Educational Research, Vol. 13, No. 1, pp. 42-54, Western Illinois University Illinois, USA. 
Altet, M (2003). Characterists, explicitly and compromises the learning practices for their contributors to their evaluation, The Documents of the Education Education, p. 31-43. https://doi.org/10.3406/dsedu.2003.1027

Aktouf, O. (1987). Methodology of the social sciences and approach qualitative of the organization. An introduction to the classroom debate and a critique. Montreal: The Press of the University of Quebec, p. 213.

Auerbach, C \& Silverstein, L. (2003). Qualitative data: An Introduction to Codingand Analysis, New York University Press.

Barbier, J.-M. (1996). The analysis of practices: conceptual questions, in C. BlanchardLaville \& D. Fablet (cord). The analysis of the professional practices, pp. 29-49. Paris: L'Harmattan.

Bardin, L. (1998). The content analysis. Paris: University press of France.

Beaucher, C. (2010). The link to knowledge of the teacher-student in the professional teaching: A case study: Social issues, Scientific issues. The new notebooks of the research in Education, Vol 3, No 1.

Beckers, J. (2007). Compétences et identité professionnelles: L'enseignement et autres métiers de l'interaction humaine. Brussels: De Boeck Superior. https://doi.org/10.3917/dbu.becke.2007.01

Ben Jomâa, H., \& Terrisse, A. (2014). The effect of an " already-there » on teacher's practice: the point of view of PE clinical didactic. Research in Education, 20, pp. 116-128.

Ben Jomâa, H. Sgair, D. \& Mami, M. (2016). The impact of personal experience on the professorial practice in Physical Education: A case study from Tunisia. Creative Education, 7, 1328-1334. http://dx.doi.org/10.4236/ce.2016.79137.

Beillerot, J. (1996). For the clinic of the link to knowledge. The Harmattan Edition.

Berelson, B. (1952). Content Analysis in Communication Research The free Press. https://doi.org/10.1086/617924

Blanchard- Laville, C. (2002). The teachers between pleasure and suffering. Paris:PUF. https://doi.org/10.3917/rfp.664.1345

Buznic-Bourgeacq, P. (2009). The transmission of experiential knowledge. Cases studies and comparative analysis in PE clinical didactic. Doctoral thesis. University of Paul Sabatier, Toulouse 3.

Buznic-Bourgeacq, P. (2016). Didactics and training of teachers. Didactic activities and subjective stakes of the novice teachers in class. In Didactics and training of teachers. B. Calmettes, M.-F. Carnus, C. Barcia-Debanc \& A. Terrisse, pp. 403-411. Brussels: PUL.

Carnus M-F \& Terrisse, A. (2013). PE clinical didactics: questioning the teacher subject. Paris: PE Editions.

Charlot, B. (1982). "Which practices for another school?", in GFEN (Coll.). Paris: Casterman E3, pp. 130-153.

Charlot, B. (1997). From the link to knowledge. Elements of a theory. Paris : Anthropos. https://doi.org/10.7202/502028ar

Chevallard, Y. (2002). Anthropological approach of the link to knowledge and mathematics didactic. Colloquium: Didactics and links to knowledge, Acts of the $3 \mathrm{rd}$ Franco-Quebecers study day of didactics. Paris: Sorbonne University.

Collerette, P. (1997). The organisational change; Theory and practice. Quebec University press.

De Léonardis, M., La Terrasse, C. \& Hermet, I. (2002). The link to knowledge: concepts and operationalization. From the link to knowledge to the school and to the university. Paris: L'Harmattan.

Dubar, C. (1991). The socialisation: The construction of social and professional identity. Paris: A. Colin. https://doi.org/10.7202/1002611ar

Durand, M. (1996). Teaching in school environment. Paris: PUF. 
Frenay, M. \& Paquay, L. (2011). Train academics in pedagogy. Research and Training, 67, pp. 105-116.. https://doi.org/10.4000/rechercheformation.1476

Frenay, M. \& Wouters, P. (2014). University pedagogy, in Dictionary of the concepts of the professionalisation, A. Jorro (dir), p-p 201-204. Brussels: Edition De Boeck Superior.

Freud, S. (1985). Construction through the analysis. In Results, ideas, problems II, pp. 268283. Paris: PUF.

Freud, S., (1925). Psychanalysis and medicine or the question of profane analysis. My life and the psychanalyse, pp. 93-184. Paris: Gallimard.

Ion, J. (1990). The social work to the test of territory. Paris: Dunod.

Jourdan, I. (2005). The evolution of the link to knowledge as a revealer of the professionalization logic: six studies cases in initial training in PE at the IUFM Midi-Pyrenees. Non published doctoral thesis. Paul Sabatier University, Toulouse.

Kunnen, E. S., \& Bosma, H. A. (2003). Fischer's Skill Theory applied to identity development: A response to Kroger. Identity, 3, 3, 247-270. 10.1207/S1532706XID0303_05

Krippendorff, K. (2003). Content analysis: an introduction to its methodology. 2emeedition, Thousand Oaks, CA, Sage Publications. https://doi.org/10.1177/1094428108324513

Labarriere, P.-J. (1990). Identity. Universal philosophic encyclopaedia. Paris: PUF.

Lacan, J. (1968). The analytic act. Lesson from $17^{\text {th }}$ of January 1968, unprecedented. DOI:www.ecole-lacaniene.net/stenos/seminaire XV bis.1968.01.17.

Loizon, D. (2009). The personal filters in didactical actions. In A. Terrisse \& M.-F. Carnus (cord), Physical Education (PE) clinical didactic. Which knowledge issues? (pp. 83100). Bruxelles: De Boeck Editions.

Martuccelli, D. (1995). Differences. Paris: PUF.

Mead, G.H. (1934). Mind, Self and Society: From the Standpoint of a Social Behaviorist, Chicago: University of Chicago Press. https://doi.org/10.1177/000271623517900175

Mucchielli, A. (1986).The identity. Paris: PUF.

Passeron J.C. \& Revel J. (2005). Thinking by case, "Enquête », Paris: School of higher Studies of social sciences.

Raymond, R., Tremblay \& Perrier, Y. (2006). Tools and methods of intellectual work. Editions Chenelière. know more Collection, $2^{\text {nd }}$ ed.

Ricoeur, P. (2005). Becoming capable, being known. Spirit, N7.

Rochex, J.-Y. (2004). The link to knowledge notion: convergences and theoretical debates. Psychological Practices, 10, 93-106. https://doi.org/10.1016/j.prps.2004.03.001

Sainsaulieu, R. (1977). The identity in work. Paris: Presses of the national Foundation of political sciences.

Saujat, F. (2004). How do the beginning teachers start the job? Questioning the training and teaching practices. HEP Revue of Suisse Romande and Tessin, 1, pp. 97-106.

Terrisse, A. (2009). PE clinical didactic. Origin, theoretical framework and empirical researches. In A. Terrisse, M.-F. Carnus, Physical Education (PE) clinical didactic. Which knowledge issues? Bruxelles: De Boëck.

Terrisse, A, \& Carnus. (2009). Physical Education (PE) clinical didactic. Which knowledge issues? Paris : De Boeck.

Tickle, L. (2000). Teacher Induction: The Way Ahead. Buckingham: Open University Press.

Touboul, A. (2011). The effects of experience and expertise in teaching practice in PE. A clinical didactic study in French Boxing. Doctoral Thesis. Toulouse University II, The Mirail. 
Trigwell, K., Prosser, M., \& Waterhouse, F. (1999). Relation between teacher's approaches to teaching and student's approaches to learning. Higher Education, 37, 1, pp. 57-70. https://doi.org/10.1023/a:1003548313194

Van der Maren, J.-M. (1996). Research methods in education (2nd ed.). Montreal: Montreal University Presses. https://doi.org/10.7202/031875ar

Vygostski, L. (1994). Defectology et mental deficiency. Lausanne: Delachaux and Niestlé.

Wanlin, P. (2007). The content analysis as a interviews qualitative analysis: A comparison between manuals and logistic using. Qualitative researches-Special. Edition, $\mathrm{N}^{\circ} 3$. Colloquium acts. Statement and qualitative research prospectives.

Wittorski, R. (2008). The professionnalisation. Knowledge, 2, pp. 9-36. https://doi.org/10.3917/savo.017.0009 